\title{
Xenía: la amistad-ritualizada de Homero a Heródoto
}

\author{
Gastón Javier Basile \\ Universidad de Buenos Aires \\ gbasile@uade.edu.ar \\ Xenia: ritualized-friendship from Homer to Herodotus
}

\begin{abstract}
Este artículo examina la construcción lingüística de la amistad-ritualizada a partir del cotejo de los poemas homéricos y de su desarrollo ulterior en las Historias de Heródoto. En primer lugar, se encuadra el fenómeno de la $\xi \varepsilon v i ́ \alpha$ en las elaboraciones teóricas de la crítica. Luego, se analizan los registros homéricos de la familia léxica organizada en torno al término ร̌́vos, a los fines de precisar las características conjuntas que presenta el lenguaje de la amistad-ritualizada en la epopeya. Por último, se señala el desarrollo particular del esquema conceptual de la $\xi \varepsilon v i ́ \alpha$ en la narración herodotea. Heródoto emplea una forma nominal abstracta,

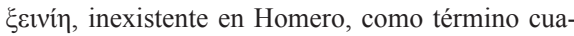
si-técnico de orden geopolítico y eminentemente secular para designar vínculos inter-aristocráticos de amistad o alianza.
\end{abstract}

Palabras clave: $\Xi$ cvía; amistad ritualizada; Homero; Heródoto.
The paper examines the linguistic configuration of ritualized-friendship through a contrastive analysis of the Homeric poems and Herodotus' Histories. First, the critical approaches to xenia in the Greek world are charted. Second, the overall characteristics of the language of ritualized-friendship in the Homeric epic are outlined through a lexical analysis of the semantic field of xenos and its cognates. Finally, the development of the conceptual framework of ritualized-friendship is traced in Herodotus' narrative. The analysis shows that Herodotus

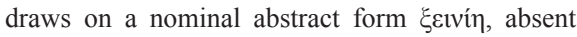
in Homer, and employs it from a geopolitical and largely secular stance, as a relatively technical term to designate inter-aristocratic bonds of friendship or alliance.

Key words: Xenia; ritualized friendship; Homer; Herodotus.

\section{INTRODUCCIÓN}

El término $\xi \xi ́ v o \varsigma$ aparece en su génesis estrechamente ligado a la institución de la $\xi \varepsilon v i ́ \alpha$ o amistad-ritualizada. El concepto parece denotar simultáneamente tanto la idea de extranjero como la de huésped, de modo que resulta vano intentar distinguir algún tipo de progresión histórica en la emergencia de dos valores

Copyright: (C) 2016 CSIC. Este es un artículo de acceso abierto distribuido bajo los términos de la licencia de uso y distribución Creative Commons Attribution (CC-by) España 3.0. 
semánticos discretos ${ }^{1}$. La aportación fundamental en materia de la institución de la $\xi \varepsilon v i ́ \alpha$ en el mundo griego corresponde a la tesis de Herman (1987), quien — abonando en las observaciones iniciales de Finley (1978) sobre la centralidad de dicho mecanismo de sociabilidad en el mundo homérico- - ofrece un exhaustivo estudio sobre los mecanismos ritualizados de interacción entre miembros de élite de diferentes unidades sociales en el período arcaico y clásico griego. Dichos lazos de amistad-ritualizada, que podían establecerse entre miembros de distintas póleis griegas, así como entre griegos y no-griegos, o entre pueblos no-griegos entre sí, son encuadrados por Herman en la intersección de un espectro más amplio de relaciones sociales definidas por Pitt-Rivers (1973) como amistosas: especialmente, las del parentesco y la amistad. Se trataba de una institución esencialmente aristocrática, entre miembros de élite pertenecientes a dos unidades sociales y políticas (al menos, simbólicamente percibidas como) diferentes. Asimismo, el vínculo de $\xi \varepsilon v i ́ \alpha$ adquiría — análogamente a las relaciones de parentesco - un carácter vitalicio y transgeneracional. Sancionada a través de una serie de rituales codificados, como la intercesión de mediadores de ambas partes, la declaración protocolar de no hostilidad y el intercambio de

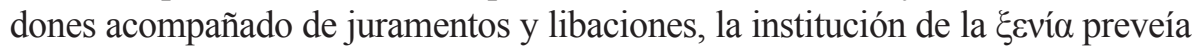
una serie de servicios y favores rituales, privados y políticos entre los contrayentes, gobernados por la lógica de la reciprocidad ${ }^{2}$. Estos lazos interpersonales, a su vez, se extendían de iure y de facto a las respectivas comunidades políticas.

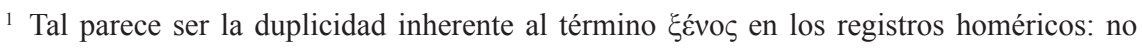
existe una oposición semántica clara entre el 'extranjero' y el 'huésped', sino que constituyen el anverso y reverso de un mismo status identitario: el individuo ajeno a la comunidad de referencia (el diferente) al que se acoge (asemeja) mediante un pacto de hospitalidad recíproco. Cf. Kakridis 1963, p. 86, en relación con el solapamiento del sentido 'extraño' y 'extranjero'. Gauthier 1973, pp. 1-21, sostiene que la ambivalencia entre 'huésped' y 'extraño-extranjero' resulta evidente en Homero y Hesíodo, de modo que descarta un desarrollo histórico según el cual del sentido de 'huésped' se habría derivado en el de 'extranjero'.

2 El fenómeno de la reciprocidad en la Antigüedad ha recibido un renovado impulso en las últimas décadas (Cf. especialmente, Gill, Postlethwaite y Seaford 1998). Si bien se trata de un concepto culturalmente variable (Mac Cormack 1976), la noción de reciprocidad ocupa un rol particularmente central en las sociedades pre-estatales, como el mundo homérico (Cf. Donlan 1981-82, 1989, 1993). Esta noción de reciprocidad podría incluso estar contenida en la propia raíz del término $\xi \dot{\varepsilon} v o s$. Schwartz 1985, pp. 487, 495 propone una forma indoeuropea

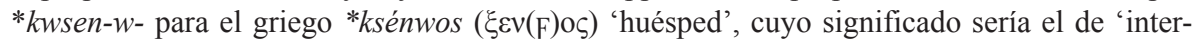
cambiar, compensar', al tiempo que rastrea una forma indoeuropea similar en formas hititas y avésticas en las que prevalece la idea de 'dar a cambio', 'compensar', etc. 
Precisamente en virtud de su asociación con la amistad-ritualizada, la noción de $\xi \dot{\varepsilon} v o \zeta$ ha sido invocada frecuentemente en discusiones vinculadas con las relaciones de $\varphi \imath \lambda i ́ \alpha$ en el mundo griego, desde los testimonios de los

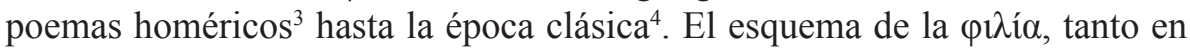
su interpretación más estrictamente subjetiva e individual de 'afecto' o 'amistad', hasta su concepción sociológico-política en términos de redes de influencias o asociaciones capaces de incidir en la gestión de los asuntos intra e interestatales, descansa en el reconocimiento de la opuesta, pero solidaria, noción de 'enemistad'. De traducción esquiva ${ }^{5}$, definida por Aristóteles como

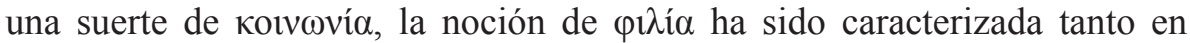
términos afectivos ${ }^{6}$ como en términos relacionales, es decir, como un sistema de obligaciones recíprocas que vinculan al individuo con la sociedad ${ }^{7}$. En los últimos años, los estudios han tendido a soslayar la carga subjetivo-afectiva

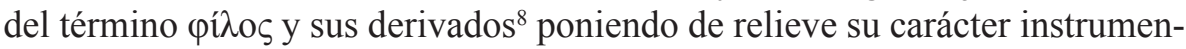
tal, contractual ${ }^{9}$. En particular, se ha explorado recientemente la idea de reciprocidad inherente a las relaciones dominadas por la $\varphi \imath \lambda i ́ \alpha$, subrayando su carácter instrumental en la gestión de las relaciones en las sociedades preestatales ${ }^{10}$. A su vez, sobre la base de teorizaciones aristotélicas, la crítica ha tendido a agrupar bajo la categoría de $\varphi \imath \lambda i ́ \alpha$ una serie de relaciones sociales

${ }^{3}$ Cf. Adkins 1960, 1972, Hooker 1987, Seaford 1994. El término $\varphi \imath \lambda i ́ \alpha$ no se registra en

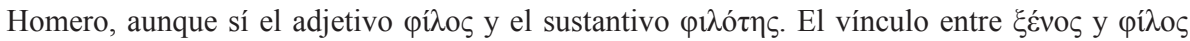
ha recibido una atención considerable por parte de la crítica, en especial en los testimonios homéricos. Benveniste 1966, p. 341, sostiene que la noción de pínos evoca el comportamiento

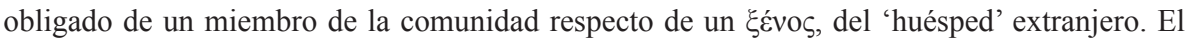
extranjero, desprovisto de protección, de amparo, de medios de supervivencia, es acogido en nombre de un pacto de $\varphi \imath \lambda o ́ \tau \eta \zeta$, inscribiéndose en un marco de prestaciones recíprocas que constituyen la 'hospitalidad'. Véanse también Kakridis 1963, pp. 41, 86-108, Adkins1963, pp. 33-45, 1972, p. 16, Karavites 1992, pp. 52-53.

${ }^{4}$ Cf. Blundell 1989, Millett 1991, Osborne 1994, pp. 139-140, Mitchell 1997, pp. 1-21.

${ }^{5}$ Cf. Millett 1991.

${ }^{6}$ Cf. Konstan 1997.

7 Cf. Benveniste 1973, pp. 257-282, Goldhill 1986, p. 82, Millett 1991, p. 114.

${ }^{8}$ Para el uso afectivo del término en época homérica, véanse Hooker 1987, Robinson 1990.

${ }^{9}$ Para la visión instrumental de la $\varphi \imath \lambda i ́ \alpha$ en Homero que designaría la esfera de posesiones del jefe del oĩkos, véase Adkins 1960, 1972, pp. 16-17, Benveniste 1969, pp. 337-353, Millett 1991, pp. 120-121.

${ }^{10}$ Cf. para la reciprocidad en Homero, Donlan 1981-82, 1989, 1993; en general, Millett 1991. 
de carácter esencialmente igualitario, horizontal y recíproco, que creaban obligaciones y derechos de ambas partes, eran susceptibles de perpetuarse en el tiempo o en sucesivas generaciones y se expresaban material y simbólicamente a través de la circulación de dones ${ }^{11}$. Dentro de estas asociaciones enmarcadas en la $\varphi \imath \lambda i ́ \alpha$ - término que se opone al conjunto de los individuos y objetos percibidos como hostiles o amenazantes al in-group ${ }^{12}$ - tradicionalmente se han incluido: 1. las relaciones de parentesco natural, en las que prevalecen relaciones de afecto en grados variables, incluso de carácter altruista, pero que igualmente se consolidan y perpetúan en virtud de la $\chi \alpha ́ \rho p \varsigma$ mutua y la reciprocación de favores y servicios; 2 . las relaciones de parentesco político (o ritual ${ }^{13}$ ) consolidadas, especialmente en época homérica, a través del intercambio de mujeres y dones ${ }^{14}$ y que garantizaban el establecimiento de alianzas políticas por matrimonio $(\kappa \eta \delta \varepsilon i ́ \alpha)$ más allá del estricto círculo de parientes de sangre ${ }^{15} ; 3$. las relaciones entre camaradas, co-

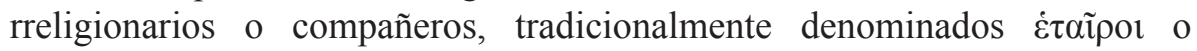

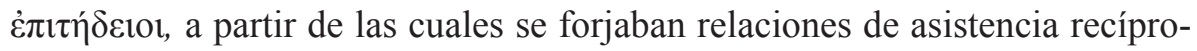
ca entre miembros de élite, de edad y status $\operatorname{similar}^{16}$. 4. Por último, incorpo-

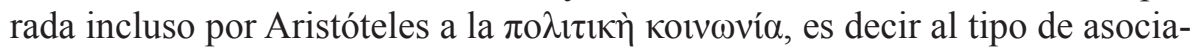
ciones políticas basadas en el provecho mutuo, la $\xi \varepsilon v i ́ \alpha$ constituye una categoría adicional de las relaciones entre píiol, signada también por la reciprocidad y horizontalidad. La peculiaridad aquí radica en el establecimiento de vínculos con un miembro extra-comunitario, rito que se hace efectivo mediante la recíproca inclusión del otro en el seno del oĩkos propio.

La mayor parte de los estudios analiza el fenómeno de la $\xi \varepsilon v i ́ \alpha$ y la interacción entre $\xi \dot{c} v o 1$ en la coyuntura de las comunidades pre-estatales, vinculando dicha práctica a los modos en los que los oĩ alianzas personales, extendían sus contactos comerciales en el extranjero e

${ }^{11}$ Cf. Gouldner 1960, p. 175, Mauss 1970, Finley 1977, p. 64, Gregory 1982, pp. 8-12, Blundell 1989, pp. 33-34, Seaford 1994, von Reden 1995, p. 60.

${ }_{12}$ Cf. Blundell 1989, p. 39.

${ }^{13}$ Cf. Pitt-Rivers 1973, p. 96.

${ }_{14}$ Véanse Lacey 1968, pp. 39-41, Morris 1986, pp. 105-110, Vernant 1965, p. 139 ss., etc.

${ }_{15}$ Dichos mecanismos de alianzas por parentesco habrían continuado en vigor en época clásica. Cf. Connor 1971, pp. 15-18.

${ }^{16}$ Al respecto, cf. Rösler 1980, Schmitt-Pantel 1990, pp. 20-22, 1997, pp. 32-34, Murray 1990, pp. 150-151, Stehle 1994, etc. Acerca del rol político desempeñado por estas alianzas

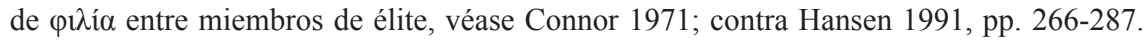


incrementaban su prestigio e influencia en sus respectivas comunidades de origen, movilizando en ocasiones a otros miembros de la comunidad cívica y política ${ }^{17}$. Con el advenimiento de la pólis, la concepción del extranjero debió acomodarse al surgimiento de un $\check{\varepsilon} \theta$ os, rol e identidad ciudadanas ${ }^{18}$. No obstante, ciertas prácticas arcaicas en relación con el establecimiento de alianzas personales con miembros de comunidades extranjeras (tanto griegas como no griegas) continuaron vigentes en la pólis, si bien se gestaban y per-

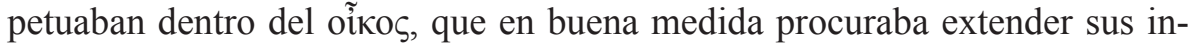
fluencias más allá de la familia nuclear o los lazos de parentesco de sangre.

Algunos estudios han indagado acerca de la relación entre $\xi \varepsilon v i ́ \alpha$ y $\varphi \imath \lambda i ́ \alpha$ en época clásica, enmarcando ambos conceptos en la coyuntura política de la ciudad-estado y, en especial, en la gestión de los asuntos inter-póleis. Herman (1987) traza una frontera estricta entre el ámbito privado — en el que se esta-

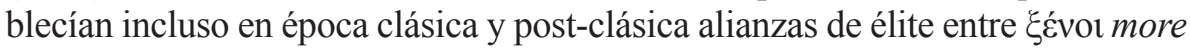
Homerico - y el ámbito público — que suponía la gestión de la res publica en interés de la pólis-. Su estudio delinea las contradicciones o el conflicto de intereses que podían derivar de la consecución de los intereses privados, por un

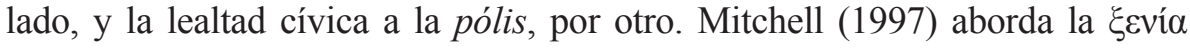
como un modo particular - junto a las relaciones de parentesco y asociaciones personales de variado tipo- de forjar redes privadas de $\varphi \imath \lambda i ́ \alpha$. Entiende que la

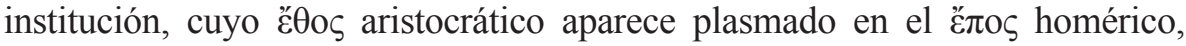
pervivió en los siglos V y IV y reprodujo una serie de conductas rituales heredadas de la edad heroica. La $\xi \varepsilon v i ́ \alpha$ fue uno de los modos de gestionar y codificar las relaciones entre individuos más allá de la comunidad de pertenencia y sirvió de modelo para otros modos de relación, por ejemplo, la $\pi \rho \rho_{\varepsilon \varepsilon v i ́ \alpha}$ (mediante la cual la pólis entablaba relaciones con un individuo para que oficiara de representante de sus intereses en el exterior). Por último, se ha explorado el papel desempeñado por la amistad-ritualizada en el establecimiento de alianzas interestatales en el período arcaico y clásico, así como mecanismo diplomático. Se ha examinado el solapamiento, solidaridad o diferenciación entre los tér-

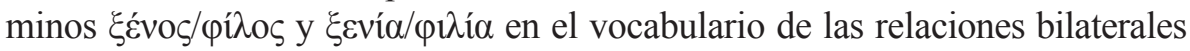
interestatales en el arco temporal que conduce desde los testimonios homéricos al siglo $\mathrm{V}^{19}$. En torno al siglo $\mathrm{V}$, en efecto, se verifica un auge del término $\varphi \imath \lambda i ́ \alpha$

\footnotetext{
${ }^{17}$ Cf. Donlan 1980, p. 14, Millett 1991, pp. 15-23, van Wees 1992, pp. 26-28, etc.

${ }_{18}$ Cf. Herman 1987, pp. 156-161, Mitchell 1997, pp. 50-55.

${ }^{19}$ Cf. Panessa 1999.
} 
- cuya ocurrencia, curiosamente, se registra por primera vez de manera sistemática en la obra de Heródoto ${ }^{20}$ — como modo de designar acuerdos bilaterales interestatales. Paralelamente, se asiste - conforme se desarrollan las relaciones comerciales entre las ciudades y se consolidan las estructuras estatales de las póleis - a la gradual caída en desuso del término $\xi \varepsilon v i ́ \alpha$ como modo de designar las alianzas de amistad, que fue reemplazado por términos como $\varphi \imath \lambda o ́ \tau \eta \varsigma^{21} \mathrm{y}$ $\varphi \imath \lambda i^{22}$ en el vocabulario diplomático.

Una de las instituciones cívicas que redefine los vínculos de amistad por hospitalidad en época clásica es la $\pi \rho o_{\varepsilon} \varepsilon v^{\prime} \alpha$, según la cual ciudadanos de un estado eran investidos por otro estado a los efectos de que intercedieran, en sus comunidades de origen, como representantes locales del estado que concedió dicha prerrogativa ${ }^{23}$. Así pues, quien otorgaba el título honorífico de $\pi \rho \xi^{\prime} \xi v 0 \varsigma$ era siempre una comunidad y quien lo recibía era un extranjero a dicha comunidad que debía velar por los intereses del estado otorgante ante las instituciones de su comunidad de residencia. Existen discusiones en relación con el grado de identificación u homologación entre la función del

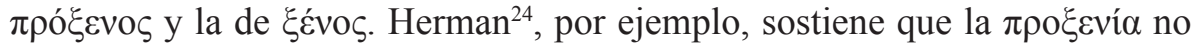
fue sino una adaptación de los modos privados de amistad-ritualizada en los que una de las partes contrayentes no era ya un individuo, sino el conjunto del cuerpo cívico, pero que necesariamente debía fundarse en lazos de $\xi \varepsilon v i ́ \alpha$ preexistentes entre individuos de ambas comunidades ${ }^{25}$. Otros autores, en cambio, ponen el acento más fuertemente sobre el carácter contractual, oficial y presuntamente impersonal del cargo, ligado a los mecanismos jurídicos de la pólis, concibiendo la $\pi \rho 0 \xi \varepsilon v i ́ \alpha$ como una prolongación de la $\xi \varepsilon v i ́ \alpha$ arcaica pero adaptada a las relaciones entre comunidades de individuos-ciudadanos ${ }^{26}$.

${ }^{20}$ El antecedente de la voz $\varphi \imath \lambda i ́ \alpha$ en época clásica es la $\varphi \imath \lambda o ́ \tau \eta \varsigma$ homérica. El término clásico $\varphi \imath \lambda i ́ \alpha$ no se documenta en Homero. Existen seis registros del término $\varphi \imath \lambda i ́ n$ en Heródoto (III 82.4, 49.1, IV 152.5, VII 130.3, 151, 152.1).

${ }^{21}$ Pocos son los registros del término $\left.\varphi \imath \lambda o ́ \tau \eta\right\rceil$ en referencia a alianzas interestatales (Cf. Hdt. II 181, Lys. II, 35, And. III, 30, D.H. II 31.1, VIII 9.3, 70.2.)

${ }^{22}$ Cf. Alonso 2007, pp. 212-214. La importancia del término $\varphi \imath \lambda i ́ \alpha$ en el establecimiento de alianzas bilaterales gobernadas por la reciprocidad ha sido puesta de relieve por Panessa 1999, Mitchell 1997, Low 2007, pp. 33-76.

${ }^{23}$ Cf. Wallace 1970, Gauthier 1972, pp. 18-27, Mosley 1973, pp. 4-7, Walbank 1978, pp. 1-9, Baslez 1984, pp.11-25, Herman 1987, pp. 130-142.

${ }^{24}$ Herman 1987, pp. 131-142.

${ }^{25}$ En contra cf. Marek 1984, p. 387.

${ }^{26}$ Cf. Gauthier 1972, p. 23, Mitchell 1997, pp. 23-37. 
Sin embargo, los límites entre las injerencias privadas y los deberes públicos de los $\pi \rho{ }^{\prime} \xi \varepsilon v o r$, sin duda, fueron permeables y, a menudo, problemáticos.

\section{El LENGUAJE DE LA EXTRANJERÍA EN LA ÉPICA HOMÉRICA}

El fenómeno de la hospitalidad en Homero ha sido ampliamente estudiado ${ }^{27}$. A continuación, intentaremos dar cuenta in nuce de algunos antecedentes homéricos de la noción de extranjería a partir de un sucinto examen de los registros de la familia léxica organizada en torno al término ǵćvos. En primer lugar, indicaremos el modo en que la épica homérica conforma discursivamente la noción de extranjero y cuáles son los rasgos adjudicados al $\xi \dot{c} v o \varsigma$ (huésped-extranjero). Luego, intentaremos precisar las características conjuntas que presenta el lenguaje de la amistad-ritualizada en la epopeya. Por último, a partir de este esbozo general, precisaremos en la sección siguiente algunos de los mecanismos de adaptación y elaboración de dicho esquema conceptual en la narración en prosa herodotea.

La condición de $\xi \xi ́ v o \varsigma$ sugiere un tipo de vínculo social caracterizado explícita o implícitamente por: 1 . su reciprocidad, reversibilidad y simetría; 2. su rasgo aristocrático e igualitario; 3 . su connotación afectiva (generalmente) positiva; 4. su carácter transgeneracional y hereditario; 5 . su institucionalidad y sanción religiosa; 6 . su condición de aliado militar, en caso de ser invocado. Dichos rasgos tienen su fundamentum en la épica homérica, género éste que codificó tempranamente el lenguaje de la $\xi \varepsilon v i ́ \alpha$ no sólo como motivo literario sino como institución social en el mundo griego desde épocas arcaicas. En efecto, un examen de los textos homéricos revela una profusa elaboración de la familia léxica vinculada a la noción de extranjería ${ }^{28}$. Entre

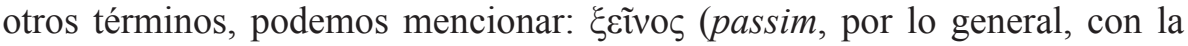

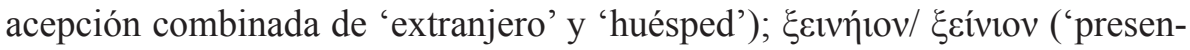

${ }^{27}$ Para un análisis reciente sobre el fenómeno de la extranjería y la condición de extranjero en el mundo griego, desde el mundo micénico hasta la época clásica tardía, véase la colección de ensayos en Santiago Álvarez y Oller Guzmán 2013. En particular, véase el artículo de Santiago Álvarez 2013, pp. 29-45, sobre la polaridad huésped/extranjero en los poemas homéricos, que desarrolla una metodología de indagación similar a la que proponemos en este artículo y cuyas conclusiones principales suscribimos. Acerca de la familia léxica de $\xi \dot{\varepsilon} v o \varsigma$ en la Ilíada y Odisea, cf. también Santiago Álvarez 2004, 2007.

${ }^{28}$ Los pasajes homéricos citados corresponden a la edición de Monro y Allen 1920. Las traducciones, en todos los casos, son nuestras. 


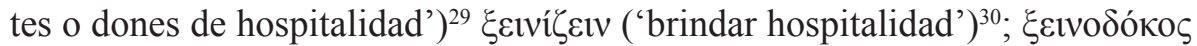

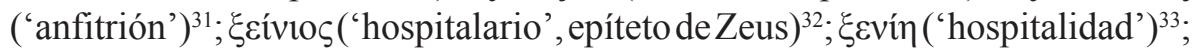

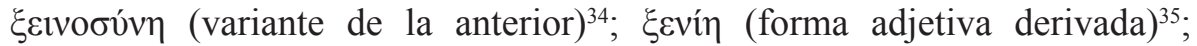

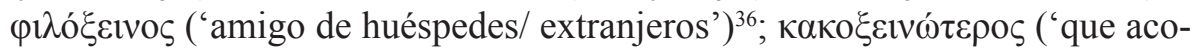
ge huéspedes de baja condición') ${ }^{37}$.

En líneas generales, ambos poemas homéricos emplean de manera sostenida el vocabulario de la $\xi \varepsilon v i ́ \alpha$ en dos sentidos complementarios: 1) como referencia a las relaciones amistosas bilaterales entre miembros de élite, de carácter transgeneracional y vitalicio; 2) como instancias en que se acoge a un recién llegado - forastero — y se lo admite en el seno del oĩ́cos a partir de una serie de prácticas rituales. Se trata, en rigor, de dos momentos de un mismo proceso: en el primer caso, se representa la amistad-ritualizada como producto de pactos previos entre miembros de comunidades extranjeras que se perpetúan en el tiempo y en el espacio; en el segundo caso, se trata de la llegada, recepción y acogimiento del huésped como acontecimiento, es decir, como despliegue narrativo de un proceso que involucra una serie de actos y gestos rituales más o menos estereotipados, descritos a su vez mediante un lenguaje formular y en un orden relativamente fijo y convencional ${ }^{38}$. Inde-

${ }^{29}$ Il. X 269 (un morrión fabricado de bovina de piel que Afidamante de Citera había dado a Molo como presente de hospitalidad), VI 218 (en relación con los dones de hospitalidad intercambiados por Eneo y Belerofontes), XVIII 408 (en relación con los dones de hospitalidad ofrecidos por Hefesto a Tetis), Od. IX 370 (irónicamente, el regalo de hospitalidad que el Cíclope ofrece a Odiseo es comérselo último de todos), etc.

${ }^{30} \mathrm{Il}$. VI 174, 217, Od. III 355.

${ }^{31}$ Od. VIII 210, 543, XV 55, Il. III 354.

32 Il.XIII 625, Od. IX 271.

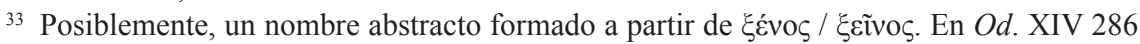
se habla de «buen hospedaje» ( $\xi \varepsilon v i ́ n ~ \alpha ̉ \gamma \alpha \theta \tilde{n})$ y en $O d$. XXIV 314 con el sentido de intercambiar

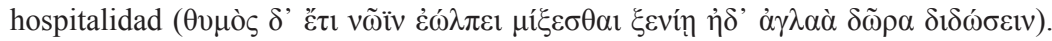

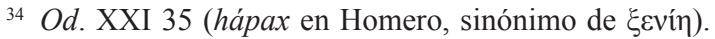

35 Od. XXIV 158, XVII 155, XX 230 (se emplea el término con valor adjetival en la

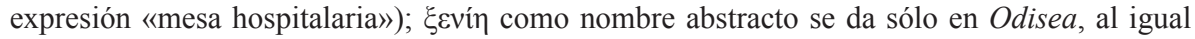

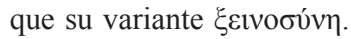

${ }^{36} \mathrm{Od}$. VI 121 (empleado como adjetivo por Odiseo para referir a los ignotos habitantes del país de los feacios), VIII 576, IX 176, XIII 202.

37 En su única aparición ( $O d$. XX 376), el adjetivo es empleado por uno de los pretendientes como término despreciativo dirigido a Telémaco por «dar hospedaje a hombres viles o de baja condición».

${ }^{38}$ Cf. Reece 1993, pp. 5-46. 
pendientemente del cariz individual que cada uno de los poemas homéricos imprime a la $\xi \varepsilon v i ́ \alpha$, resulta evidente que no se trata meramente de un tópos literario sino más bien del reflejo de una institución social, literariamente elaborada, que reenvía a prácticas interpersonales efectivas propias de un estadio anterior al advenimiento de la pólis.

Los testimonios homéricos constituyen la matriz generativa de la noción de $\xi \dot{\varepsilon} v o \varsigma$ (extranjero/ huésped), así como un reflejo de las prácticas socioculturales de época arcaica en el marco de las cuales se cifró la concepción del otro como igual de clase. Tal representación aristocrática del otro pervivió en el imaginario griego, incluso en época clásica. Y no permaneció confinada solamente a un modo de expresión, o a un conjunto de rasgos o escenas tipificadas sobre la relación con el extranjero reservadas puramente a un plano literario o imaginario tributario de la épica homérica, sino que se plasmó en prácticas sociales concretas que legitimaban un cierto modo de relación con el extranjero aún en el siglo v y que, pronto, comenzaron a entrar en conflicto o - articularse de modos diversos - con los intereses comunes de la totalidad del cuerpo político (la pólis). Ahora bien, resta por considerar en qué medida los poemas homéricos efectivamente codifican - a partir del desarrollo de un término ad hoc - la noción abstracta de amistad-ritualizada ( $\xi \varepsilon v i ́ \alpha)$ como un mecanismo institucionalizado de acogida del extranjero y regulación de las relaciones inter-aristocráticas, o bien se trata de una conceptualización posterior de época arcaica y clásica que reelabora el lenguaje de la extranjería propio de la epopeya y que cristaliza en el marco de prácticas diplomáticas y de relaciones interestatales. Un examen de los empleos en

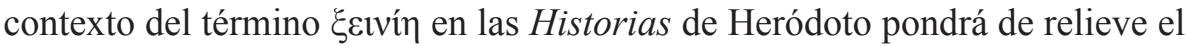
desarrollo ulterior de dicho esquema conceptual, en consonancia con prácticas institucionalizadas de época arcaica y clásica, así como una serie de rupturas y continuidades respecto de la epopeya.

\section{El Lenguaje de la eXtranjería en Heródoto}

Heródoto emplea en los sucesivos lógoi el término ǵv́vos, así como otros términos vinculados a la extranjería, de manera proficua en amplias secciones del relato. Por cuestiones de espacio, nos limitaremos aquí a examinar una serie de pasajes

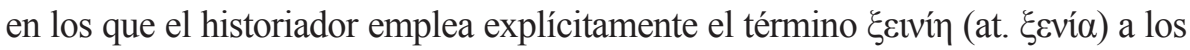
efectos de deslindar los modos en que la obra de Heródoto reconfigura el vocabulario de la amistad-ritualizada en su relato de las relaciones interpersonales entre 
líderes griegos y no griegos en el período arcaico y clásico. Dicho testimonio lingüístico por parte de Heródoto permite asimismo especular acerca del desarrollo de la amistad por hospitalidad en época clásica, así como los mecanismos y la finalidad del establecimiento de relaciones inter-póleis y gestiones diplomáticas. Analizamos a continuación una selección de pasajes significativos ${ }^{39}$.

I 69. Heródoto relata en este pasaje la alianza entre Creso y los lacedemonios mediante el lenguaje de la amistad-ritualizada ${ }^{40}$. Creso envía emisarios a

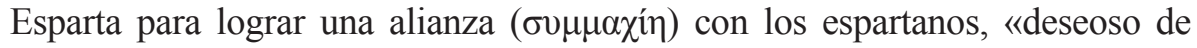

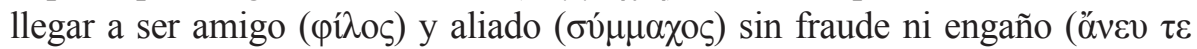

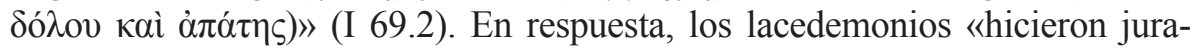

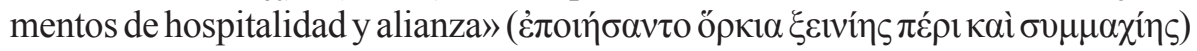
(I 69.3). El paralelismo sintáctico entre el discurso de los emisarios de Creso

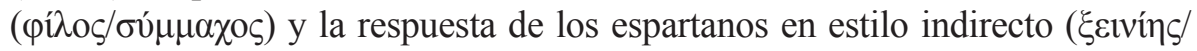
$\sigma o \mu \mu \alpha \chi i n \varsigma)$ permite evidenciar el modo en que el pedido de amistad/alianza - expresado mediante el adjetivo pí $\lambda$ os — es reformulado por los espartanos (a través de la voz enunciadora) en términos de $\xi \varepsilon v i ́ \alpha$. Cabe destacar en este pasaje una serie de elementos propios de la alianza entre Creso y los espartanos que reproducen mutatis mutandis el vocabulario de la amistad-ritualizada codificado por la épica homérica: 1 . la referencia a términos vinculados al campo

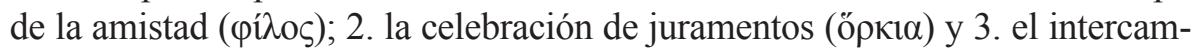

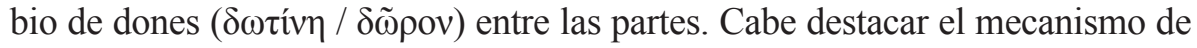
reciprocidad puesto de relieve por Heródoto como uno de los móviles de la alianza: los lacedemonios estaban obligados ( $\varepsilon \tilde{i} \chi 0 v)$ por ciertos beneficios an-

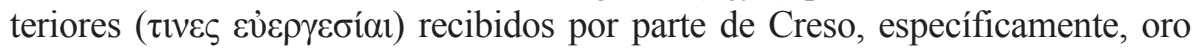
que Creso había entregado como regalo (ž $\delta \omega \kappa \varepsilon \delta \omega \tau i ́ v \eta v)$ a emisarios espartanos enviados a Sardes. Los lacedemonios retribuyen quid pro quo sellando la

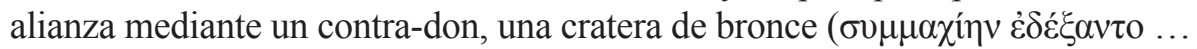

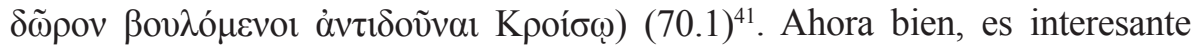

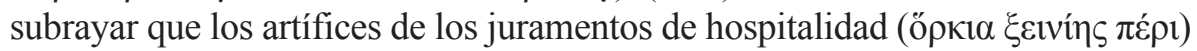

${ }^{39}$ Los pasajes de Heródoto citados en nuestro estudio corresponden a la edición de Hude, 1927. Las traducciones, en todos los casos, son nuestras.

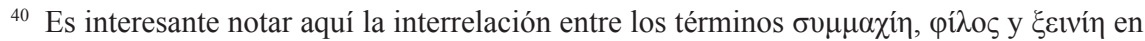
la narración de una alianza interestatal, que se verifica también en el desarrollo del vocabulario diplomático entre época arcaica y clásica.

${ }^{41}$ El término $\sigma 0 \mu \mu \alpha \chi i ́$, inexistente en Homero, designaba originariamente una alianza

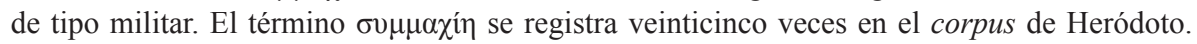
Sobre la evolución del término, cf. Tausend 1992, pp. 188-256. 
son presentados, desde el plano del enunciado, como los lacedemonios en su conjunto, y no como un sujeto singular.

III 39-43. En el marco de uno ${ }^{42}$ de los lógoi samios insertos por Heródoto en el libro III (III 39-60), se desarrolla la relación de amistad interpersonal entre el rey egipcio Amasis y Polícrates, tirano de Samos entre el 533 y el 522 a. C. Nuevamente Heródoto emplea aquí el esquema conceptual de la

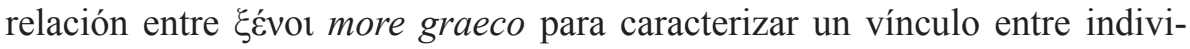
duos de élite en época arcaica. Citemos los pasajes más significativos.

Heródoto, tras introducir la figura de Polícrates, explica el modo en que

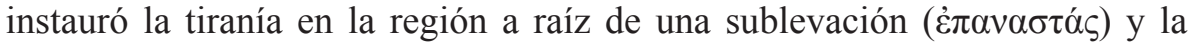
celebración del pacto de amistad con Amasis:

... habiéndose apoderado (de toda la isla de Samos) entabló (Polícrates) una

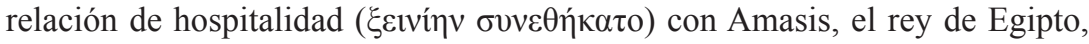
enviando dones $(\delta \tilde{\omega} \rho \alpha)$ y recibiéndolos de parte de aquél. (III 39.2)

Conforme Polícrates acrecienta sus dominios en las islas y algunas ciudades del continente, su huésped-extranjero, Amasis, comienza a inquietarse

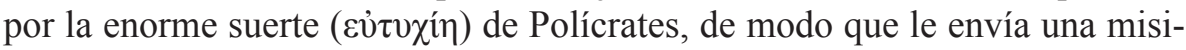
va advirtiéndole del $\varphi \theta$ óvoৎ divino — admonición ésta consustancial al pensamiento arcaico y que Heródoto tematiza ampliamente - :

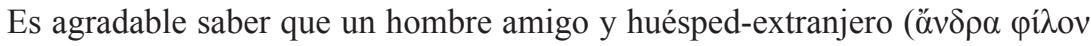

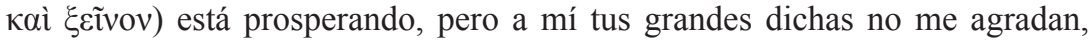
pues sé que la divinidad (

Amasis aconseja a Polícrates desembarazarse de un objeto propio de gran valor como modo de contrarrestar su buena fortuna. Polícrates intenta en vano deshacerse de un sello engastado en oro que, no obstante, le es devuelto por un pescador. Enterado de esto, y comprendiendo que Polícrates no habría de tener un final feliz (augurio éste que se verificará en III 120-125), Amasis decide disolver la relación de $\xi \varepsilon v i ́ \alpha$ :

${ }^{42}$ Heródoto introduce en la historia de Persia un largo excursus (III 39-60), cuyo núcleo temático fundamental es la expedición espartana contra Polícrates (cuya duración puede ubicarse entre los años 525 y 522 a. C.). Asimismo, se insertan en este excursus dos digresiones individuales sobre Polícrates de Samos (III 39-43) y Periandro de Corinto (III 48-53). Sobre los lógoi samios de Heródoto, véase Cobet 1971, pp. 195-163, Immerwahr 1957, pp. 312-322; sobre el carácter tendencioso de los informantes del historiador, cf. Mitchell 1975, pp. 75-91. 
Entonces, enviándole un heraldo a Samos, dijo que disolvía la hospitalidad

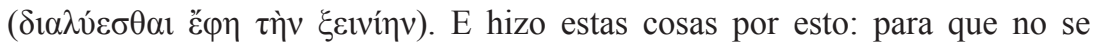
afligiera él mismo (e.d. Amasis) en el alma, como (se afligiría uno) en relación

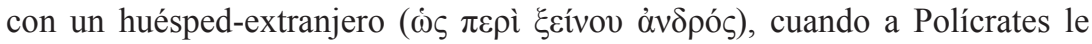
sobreviniera una terrible y enorme desgracia. (III 43.2)

Cabe destacar aquí una serie de elementos vinculados a la tradicional re-

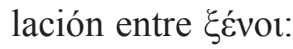

a) La horizontalidad que rige el lazo social inter-aristocrático. En este caso, es importante señalar que la alianza se establece entre un rey (no-griego) y un tirano (griego) $)^{43}$.

b) La reciprocidad que gobierna la relación hasta su disolución por parte de Amasis; la conformación de la alianza a partir del intercambio de

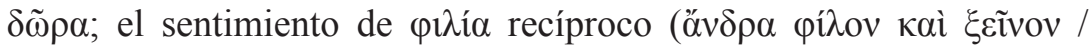

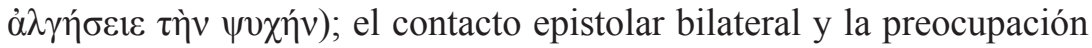

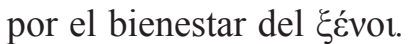

c) La excepcional disolución ${ }^{44}$ del vínculo por parte de Amasis, justificada en términos religioso-afectivos: la ưßpıৎ de Polícrates desencadenará de modo ineluctable el $\varphi \theta$ óvos de la divinidad.

V 29-33. En el relato de los antecedentes inmediatos de la «sublevación jonia» ${ }^{45}$, el término $\xi \dot{\varepsilon} v o \varsigma$ es empleado para designar los lazos de hospitalidad existentes entre Histieo, tirano de Mileto, y aristócratas desterrados por la

43 En rigor, Jonia constituye un territorio de frontera entre el mundo griego y nogriego, donde cohabitan etnias diversas. En relación con la identidad jónica en el debate cultural y político del siglo v, cf. Corsaro 1991, pp. 41-55. Sobre la importancia estructural de los jonios en el desarrollo de la trama herodotea, apenas menor a la atención concedida a Atenas y Esparta, cf. Immerwahr 1966, p. 230, Neville 1979, pp. 260-270, Stadter 1992, p. 803.

44 Al respecto, cf. Herman 1987, pp. 17, 71-72 y 135. Otro caso de disolución del pacto de $\xi \varepsilon v i ́ \alpha$-expresada asimismo por medio del verbo $\delta 1 \alpha \lambda \hat{v} \omega$ - ocurre en IV 154.4.

45 El relato de la 'sublevación jonia' ofrecido por Heródoto ha suscitado ciertas perplejidades por parte de la crítica. Se ha señalado, entre otras cosas, el hecho de que el historiador de Halicarnaso focalice su narración en torno a las motivaciones personales de los tiranos del Asia Menor, como Aristágoras e Histieo, en lugar de enfatizar la voluntad de las ciudades griegas de Jonia de independizarse del yugo persa y de instaurar regímenes democráticos. Cf. Tozzi 1978, Murray 1988. 
facción democrática de la isla de $\operatorname{Naxos}^{46}$. Dado que, según indica Heródoto, Histieo por aquella época (en torno al 500 a. C. ${ }^{47}$ ) se encontraba retenido en

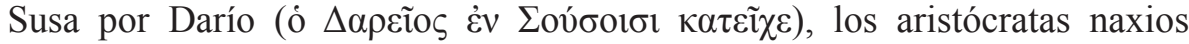
( $\alpha \nu \delta \rho \varepsilon \varsigma \tau \tilde{\omega} v \pi \alpha \chi \varepsilon \dot{\varepsilon} \omega v$ ) se presentan ante Aristágoras, yerno y primo de Histieo,

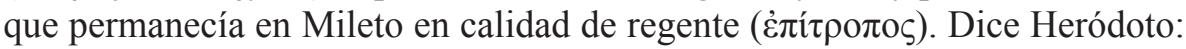
«En efecto, Histieo era tirano de Mileto, pero resultó que por casualidad en aquel tiempo - cuando llegaron los naxios que eran huéspedes-extranjeros

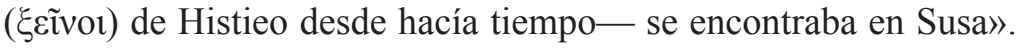

La responsabilidad del vínculo de hospitalidad recaería entonces sobre Aristágoras, al estar ausente Histeo. Según Heródoto ${ }^{48}$, la relación de $\xi \varepsilon v i ́ \alpha$ es utilizada por Aristágoras como pretexto ( $\sigma \kappa \tilde{\eta} \psi 1 \varsigma)$ para apoderarse de la isla de Naxos y erigirse como tirano: «Entonces Aristágoras, considerando que, si por su intervención (los aristócratas) regresaban a la ciudad, (él) podría

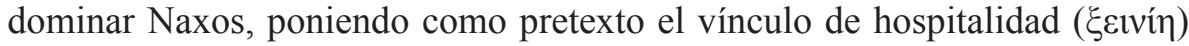
con Histieo, les dirigía este discurso» (V 30.3).

El pasaje expone a las claras el entramado de alianzas y lealtades cruzadas en Asia Menor en torno a finales del siglo VI y principios del siglo V, que Heródoto describe mediante el lenguaje de la amistad-ritualizada ${ }^{49}: 1$. Histieo de Mileto, quien había sido recompensado ${ }^{50}$ por Darío con la ciudad de Mir-

46 Scott 2005, p. 54, cita a Keinast 2002, pp. 2-3, quien indica que tal relación de hospitalidad debió fundarse en duraderos lazos comerciales entre dos prósperas ciudades jonias.

${ }^{47}$ Sobre la incierta cronología de la susodicha revuelta jonia, cf. Hammond 1955, pp. 385 ss.

${ }^{48}$ Los historiadores modernos creen que fue precisamente el llamamiento de los naxios el origen de la revuelta: «Aristágoras, sin duda, esperaba que la operación sería encomendada a los contingentes navales griegos exclusivamente, que a él se le confiaría el mando y que esta movilización podría ser desviada de su objetivo principal» (Will 1997, pp. 79-80). Cf. también Evans 1963, pp. 113-128, quien subraya el factor sorpresa del plan de Aristágoras en la revuelta contra el dominio persa.

${ }^{49} \mathrm{Al}$ respecto, cf. Munson 2007, p. 157.

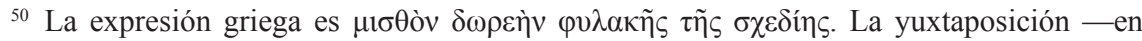
apariencia contradictoria o tautológica- de los términos $\mu 1 \sigma \theta$ ó $($ ('pago, recompensa por un

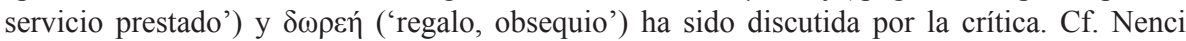
1994, von Reden 1995, p. 93, Greenwood 2007, pp. 138-139. En general, se entiende que la aparente gratuidad del don impone una obligación de reciprocidad, que equivale a un 'pago'. La crítica ha señalado que, si dentro del imaginario griego la yuxtaposición de los términos

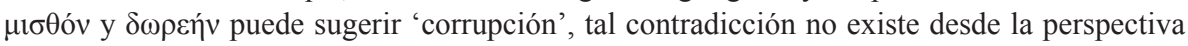
persa. 
cino por haber custodiado el puente de barcas ${ }^{51}$, es llamado por el Gran Rey (V 24.3) «amigo inteligente y solícito» (ảvì $\rho$ pí sin embargo, advertido Darío del error estratégico que implicó la concesión de tierras de gran riqueza en la zona costera de Tracia a un griego, invita a Histieo a retirarse a Susa como su compañero de mesa ( $\sigma$ $\sigma \sigma ı \tau \varsigma)$ ) y consejero $(\sigma u ́ \mu \beta 0 v \lambda \circ \varsigma)^{52} ; 2$. Aristágoras, vinculado por lazos de parentesco con Histieo, abraza la relación de $\xi \varepsilon v i ́ \alpha$ con los aristócratas naxios (interposita persona), al tiempo que se declara pí $\lambda$ os de Artafrenes, hermano de Darío, quien estaba al mando de todas las zonas costeras de Asia (V 30.5).

VII 116. En el avance del ejército de Jerjes, el Gran Rey hace «huéspedes» suyos a los habitantes de Acanto, en el istmo de la península de Acté, la más oriental de la Calcídica:

Cuando llegó, pues, a Acanto, Jerjes proclamó la hospitalidad con los acantios

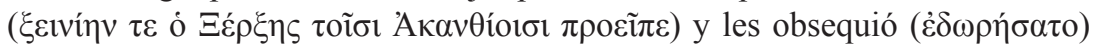
con un atuendo medo y los elogió ...

Nuevamente, la concesión de dones refuerza aquí la condición de $\xi \varepsilon ́ v o r$

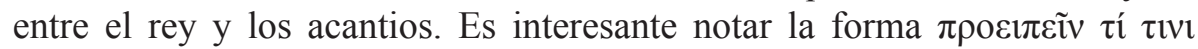
empleada en este contexto para referirse al acto de 'declarar', 'anunciar' (aunque también 'prescribir') la hospitalidad. Por un lado, la locución —en la acepción de 'declarar la hospitalidad / amistad'- puede aludir al acto de habla performativo que subyace al establecimiento de una alianza entre $\xi \dot{\varepsilon}$ vot. En efecto, $\pi \rho \circ \sigma \alpha \gamma o \rho \varepsilon v ́ \omega$ es empleado en griego con la fuerza ilocucionaria

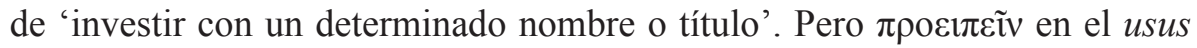
herodoteo por lo general reviste una fuerza ilocucionaria directiva, y es empleado con el sentido de 'dar una orden'. La ambigüedad apunta pues tanto al acto público de 'nombrar' '̌́vvos al otro, uno de los modos en que las fuentes indican el inicio de la amistad-ritualizada, así como a la asimetría

${ }^{51}$ Cf. V11.1.

${ }^{52}$ La relación entre Histieo y Darío demuestra la imprecisión del lenguaje de la $\xi \varepsilon v i ́ \alpha$, adoptado por Heródoto, para dar cuenta de un vínculo de tipo vertical patronus / cliens (que es, evidentemente, como los persas definirían la relación con sus súbditos). Sin embargo, tanto el

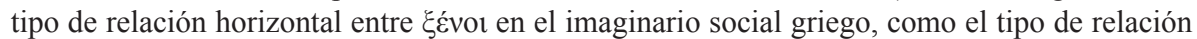
vertical entre patronus / cliens correspondiente a la usanza persa prosperaban en virtud de la lógica quid pro quo, es decir, la restitución de favores y servicios entre las partes. Acerca de la estrecha relación de amistad entre Darío e Histieo, quien gozó del inusitado privilegio de ser considerado 'benefactor' del Gran Rey, cf. Austin 1990, pp. 302-303. 
- en el sentido de coacción o imposición por parte del rey persa- en el establecimiento de esta alianza en particular; asimetría que sugiere más una expresión eufemística de colaboración forzada o sumisión por parte de los acantios que una genuina relación horizontal y voluntaria de alianza.

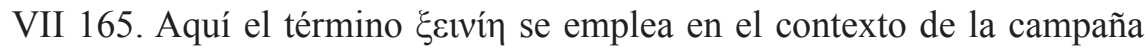
de Terilo ${ }^{53}$, tirano de Hímera expulsado de su ciudad, contra Gelón de Siracusa. Las huestes, lideradas por Amílcar, hijo de Hannón, rey de los cartagineses, estaban vinculadas a partir de alianzas particulares de $\xi \varepsilon v i ́ \alpha$ con Terilo.

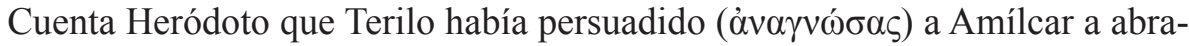

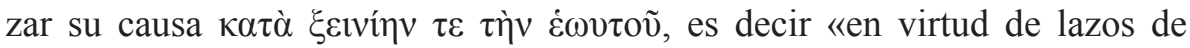
hospitalidad de él mismo (y Amílcar)» ${ }^{54}$.

VIII 120. En el contexto de la retirada de Jerjes, tras la derrota en Salamina, Jerjes entabla una relación de hospitalidad ( $\xi \varepsilon v i ́ \alpha)$ con los habitantes de Abdera, ciudad de la costa Tracia, al este de Eyón ${ }^{55}$ :

Es sabido que, habiendo llegado a Abdera en su viaje de regreso, Jerjes enta-

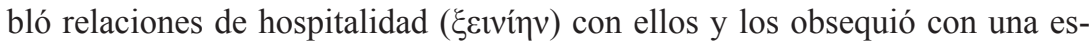
pada dorada y una tiara ornamentada con oro.

Nuevamente aquí se pone de relieve la relación entre la declaración de hospitalidad y la concomitante entrega de obsequios. Es interesante destacar que la expresión $\xi \varepsilon ı v i ́ \eta v ~ \sigma v v \tau i ́ \theta \varepsilon \sigma \theta \alpha$ rige por lo general un complemento en dativo en el usus herodoteo (cf. I 27.5, III 39.2). En la cita en cuestión el pronombre personal $\sigma \varphi \mathrm{l}$ carece de un referente anafórico en el entorno verbal del pasaje, pero se entiende que el referente ad sensum son los habitantes de Abdera. El vocabulario de las relaciones inter-aristocráticas de élite —originariamente empleado para nombrar el vínculo entre dos individuos pro-

${ }^{53}$ Nada se sabe sobre Terilo a excepción de los datos que suministra Heródoto ad locum. Fue tirano de Himera entre 488 y 471 a. C. Cf. How y Wells 1936, II, p. 200.

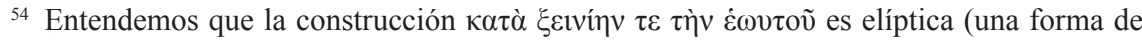

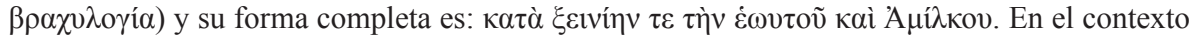
del pasaje, el referente Amílcar —elidido del segundo miembro del complemento en caso

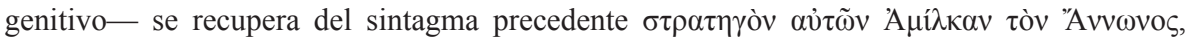

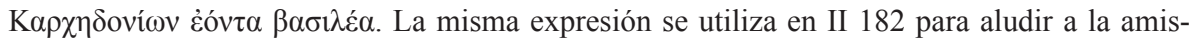
tad-ritualizada entre Amasis y Polícrates (aunque aquí sí se expresan en genitivo ambas partes

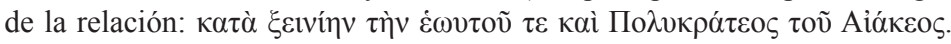

${ }^{55}$ Es probable que dicha alianza de amistad se hubiera celebrado no en la retirada de Jerjes, sino en la incursión de Jerjes en Tracia (VII 109). 
minentes de comunidades extranjeras - es empleado aquí para designar alianzas o acuerdos de cooperación interestatales. Sin dudas, se trata de una expresión por sinécdoque: quienes celebrarían el presunto pacto de no-hostilidad eran los respectivos soberanos de ambos pueblos. En Heródoto, se re-

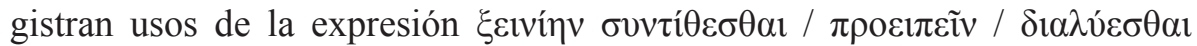
tanto para aludir a una relación interpersonal stricto sensu entre dos aristócratas griegos como para remitir a una alianza de amistad entre dos soberanos, o bien un soberano y otro pueblo - tanto de orígenes griegos como no griegos -56 .

\section{Conclusiones}

Un examen detallado de los modos de apropiación y reelaboración del esquema conceptual de la $\xi \varepsilon v i ́ \alpha$ more Homerico por parte del nuevo lógos de Heródoto merecería un estudio aparte. Existe un prolífico uso de términos

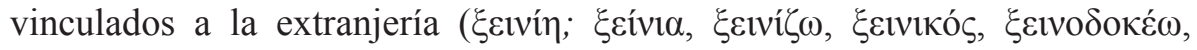
$\xi \varepsilon เ v о \kappa \tau o v \varepsilon ́(\omega, \xi \varepsilon เ v o \tilde{\mu} \alpha$ ) por parte de Heródoto, que adquieren primacía en extensas secciones del relato. En líneas generales, tan solo podemos afirmar aquí que los términos asociados a la familia léxica de $\xi \xi ́ v o \varsigma$ suelen evocar en Heródoto - en consonancia con la matriz conceptual heredada de la práctica de la amistad-ritualizada - algún tipo de lazo de hospitalidad, de alianza formal o informal, de reciprocidad o de 'vínculo de cooperación o amistad' en sentido amplio, tanto entre individuos como entre comunidades (griegos o no-griegos). Ahora bien, a partir del estudio comparado de la elaboración del lenguaje de la amistad-ritualizada en los poemas homéricos y su desarrollo ulterior en la iotopín de Heródoto - específicamente aquí el uso del término $\xi \varepsilon v i$ í-, es posible formular una serie de observaciones finales.

1. Una de las particularidades del registro léxico en Heródoto es que el lenguaje de la amistad-ritualizada se abre al escenario geopolítico, trascendiendo en ocasiones el vínculo estrictamente interpersonal more Homerico,

${ }^{56}$ I 27.5 (Creso establece una alianza con los jonios de las islas), I 69.3 (los lacedemonios se alían con Creso), II 182 (entre Amasis y Polícrates), III 39.2 (Amasis y Polícrates), III 43.2 (la disolución de la amistad entre Amasis y Polícrates), IV 154.4 (la disolución de la amistad entre Etearco y Temisón), V 30.3 (Histieo y los aristócratas naxios), VII 116 (Jerjes y los acantios), VII 165 (Terilo y Amílcar), VII 228.4 (Megistias y Simónides de Ceos), VIII 120 (Jerjes y los habitantes de Abdera). 
para comenzar a designar alianzas entre comunidades, pueblos o facciones políticas. Si bien en la epopeya las obligaciones contraídas por miembros de élite involucraban de facto al cuerpo cívico y permitían generar lazos interétnicos y movilizar grandes grupos armados en contextos bélicos, el lenguaje de la amistad ritualizada se emplea en los poemas homéricos esencialmente en singular, es decir, para designar relaciones recíprocas entre individuos. En cambio, en Heródoto el lenguaje de la $\xi \varepsilon v i ́ \alpha$ se encuadra de manera explícita en el contexto amplio de las relaciones diplomáticas interestatales, articulándose a otros términos como $\varphi \imath \lambda i ́ \alpha$ o $\sigma v \mu \mu \alpha \chi i \alpha^{57}$. Cierto es que, en gran parte de los usos en contexto, se trata de un empleo metonímico (totum pro parte): quienes establecen alianzas de amistad — aun cuando se indique un agente colectivo- son los respectivos aristócratas de ambas partes (soberanos, caudillos o líderes de las facciones en cuestión, en un amplio abanico que equipara tanto a griegos como no griegos) en nombre del conjunto del cuerpo social. Es pues el individuo - en virtud de su inscripción en la díada

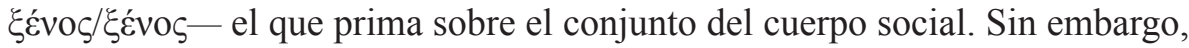
es innegable que el vocabulario de la amistad-ritualizada se emplea en las Historias de Heródoto con explícitas connotaciones geopolíticas ausentes en la epopeya.

2. En consonancia con los requerimientos del nuevo lógos instaurado por Heródoto y de las transformaciones acaecidas en el transcurso del período arcaico y clásico, el lenguaje de la $\xi \varepsilon v i ́ \alpha$ en las Historias se desplaza sensiblemente hacia el plano político-humano (para hacer alusión a mecanismos de alianza o cooperación interestatales) y se distancia de la esfera religiosa, central en los poemas homéricos. El elemento religioso en las Historias pervive, con todo, en las referencias al ritual de iniciación de la alianza: la declaración de no hostilidad, expresada como 'favor' o 'acto generoso'

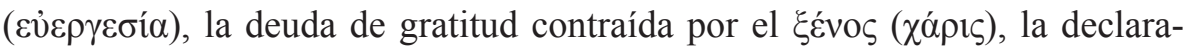

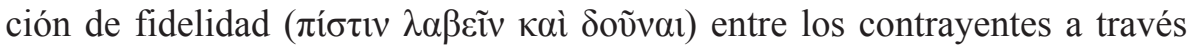
del intercambio de dones $(\pi \imath \sigma \tau \alpha)$, la pronunciación mutua de juramentos (ӧ $\kappa \kappa \iota \alpha)$ y las libaciones ( $\sigma \pi \circ \nu \delta \alpha i ́)$. En todo el proceso los dioses eran convocados ritualmente a velar por el pacto. De allí que las infracciones a los deberes de hospitalidad sean también enunciadas mediante un lenguaje religioso.

${ }^{57}$ Sobre la articulación de los términos en la tratadística y diplomacia, cf. Panessa 1999, pp. XV-XXXIII, quien señala la paulatina caída en desuso del término $\xi \varepsilon v i ́ \alpha$ y el surgimiento

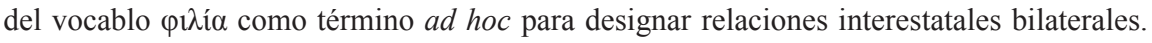


A pesar de que el elemento religioso es una constante tanto en el mundo homérico como en períodos posteriores, en el encuadre narrativo de Heródoto es la valoración secular y política de la amistad-ritualizada la que cobra preponderancia frente a la dimensión religiosa e individual de la institución que prioriza la representación homérica.

3. Una de las transformaciones fundamentales, en nuestra opinión, que ocurre en el proceso de desarrollo del lenguaje de la amistad-ritualizada more Homerico tiene que ver, precisamente, con el término $\xi \varepsilon v v^{\prime} \eta^{58}$. Homero - según hemos notado- hace un extenso uso de la familia léxica de la hospitalidad en sentido amplio (en ambos poemas, pero especialmente en la Odisea). Sin embargo, resulta debatible el hecho de que exista en efecto una concep-

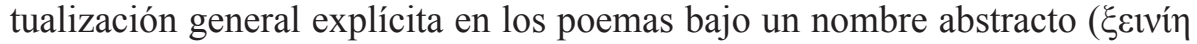

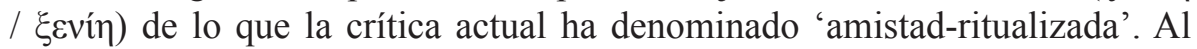
respecto, el análisis del vocabulario de la extranjería en los poemas homéri$\cos$ - sintéticamente presentado en este estudio - ofrece una sugerente prueba ex silentio. Sólo en Odisea (XXIV 286, 314) aparece, apenas en dos ocasiones, una forma nominal $\xi \varepsilon v i ́ n$ — curiosamente, sin el alargamiento com-

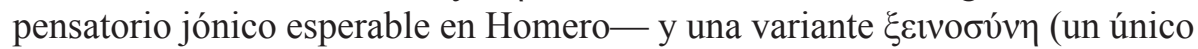
registro en $O d$. XXI 35). El término no se registra en Ilíada. La forma adjetiva $\xi \varepsilon v i ́ \eta$, por su parte, aparece en tres expresiones formulares idénticas

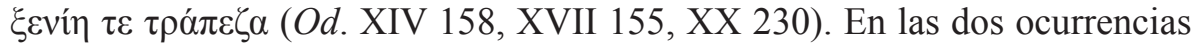

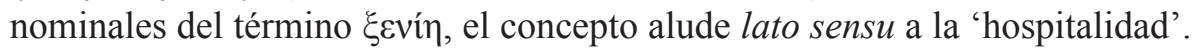
En Od. XXIV 286 se habla de 'buen hospedaje' ( $\xi \varepsilon v i ́ n ~ a ̀ \gamma \alpha \theta \tilde{n})$ y en $O d$. XXIV

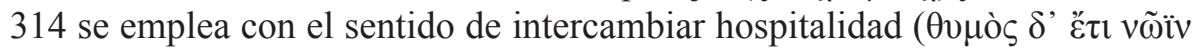

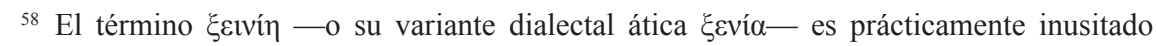
en testimonios literarios anteriores a Heródoto. Con posterioridad a los poemas homéricos,

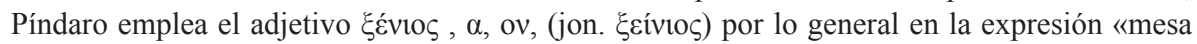

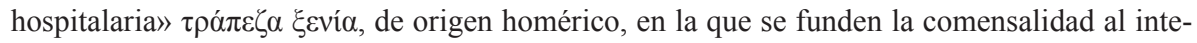
rior del círculo de iguales y el deber de hospitalidad hacia el extranjero. Por ejemplo, pí $\lambda$ oı $\sigma$ r

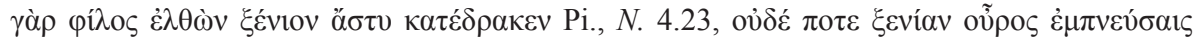

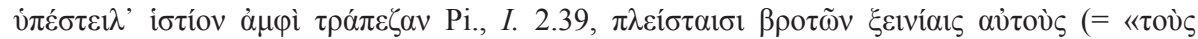

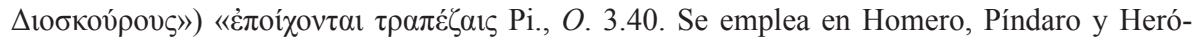

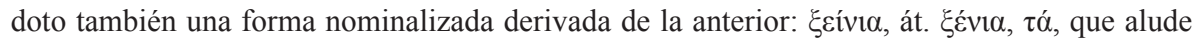
a los dones de la hospitalidad — especialmente comida y bebida — ofrecidos por el anfitrión a su huésped. Existe también, en el corpus trágico anterior a Heródoto, un único registro de

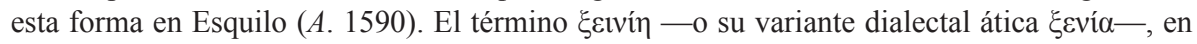
cambio, es prácticamente inusitado en los testimonios pre-herodoteos, con excepción de las formas homéricas comentadas ad locum (cf. supra). 


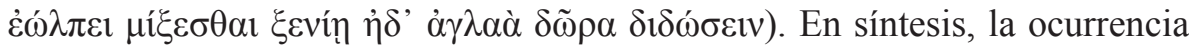

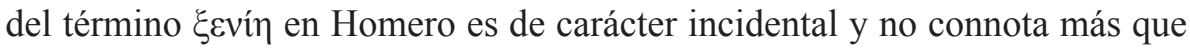
la idea de hospitalidad en un sentido amplio. En Heródoto, en cambio, el inusitado y poco utilizado término homérico $\xi \varepsilon v i ́ n$ se emplea, en su forma

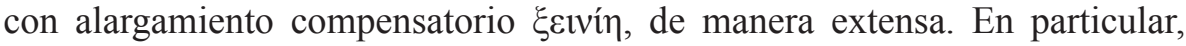

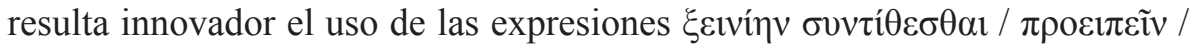
$\delta 1 \alpha \lambda v \varepsilon \varepsilon \sigma \theta \alpha$ tanto para aludir a relaciones interpersonales stricto sensu entre dos aristócratas griegos como para remitir a una alianza de amistad entre dos soberanos, o bien un soberano y otro pueblo - tanto de orígenes griegos

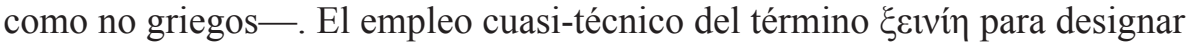
de manera genérica un vínculo inter-aristocrático de amistad o alianza - mediante el cual, por extensión, se establecen relaciones interestatales - constituye un desarrollo semántico que encuentra su primera expresión literaria en Heródoto. Dicho de otro modo, la codificación de lo que la crítica moderna ha denominado la 'amistad-ritualizada' como una práctica inherente al mundo griego desde los testimonios homéricos encuentra en Heródoto su expre-

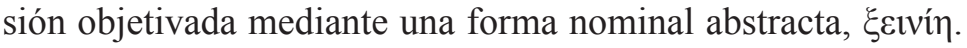

\section{BIBLIOGRAFÍA}

Adkins, A. W. 1960: Merit and Responsibility: A Study in Greek Values, Oxford.

Adkins, A. W. 1963: «Friendship and Self-suficiency in Homer and Aristotle», CQ 13 , pp. $30-45$.

Adkins, A. W. 1972: Moral values and Political Behaviour in Ancient Greece: From Homer to the End of the Fifth Century, Londres.

Alonso, V. 2007: «War, Peace, and International Law in Ancient Greece,» en Raaflaub, K. A. (ed.) War and Peace in the Ancient World, Oxford, pp. 206-225

Austin, M. M. 1990: «Greek tyrants and the Persians, 546-479 B. C.», CQ 40, pp. 289-306.

Baslez, M. F. 1984: L'étranger dans la Grèce antique, París.

Benveniste, E. 1966: Problèmes de linguistique générale, París.

Benveniste, E. 1969: Le vocabulaire des institutions indo-européennes, 1: Economie, Parenté, Société; 2: Pouvoir, Droit, Religion, París.

Benveniste, E. 1973: Indo-European Language and Society, Londres.

Blundell, M. W. 1989: Helping friends and harming enemies. A study in Sophocles and Greek ethics, Cambridge.

Cobet, J. 1971: Herodots Exkurse und die Frage der Einheit seines Werkes Historia, Wiesbaden. 
Connor, W. R. 1971: The New Politicians of Fifth-Century Athens, Princeton, Nueva Jersey.

Corsaro, M. 1991: «Gli Ioni tra Greci e Persiani. Il problema dell'identità ionica nel dibattito culturale e politico del V secolo», en Sancisi-Weerdenburg, H. y Kuhrt, A. (eds.) Achaemenid history VI. Asia Minor and Egypt: Old Cultures in a New Empire. Proceedings of the Groningen Achaemenid history workshop, Leiden, pp. 4-55.

Donlan, W. 1980: The Aristocratic ideal in ancient Greece. Attitudes of superiority from Homer to the end of the fifth century B. C, Lawrence, K.A.

Donlan, W. 1981-82: «Reciprocities in Homer», $C W$ 75, pp. 137-175.

Donlan, W. 1989: «The Pre-State Community in Greece», SO 64, pp. 5-29.

Donlan, W. 1993: «Duelling with Gifts in the Iliad: As the Audience Saw it», Coby Quarterly 29, pp. 155-172.

Donlan, W. 1998: «Political Reciprocity in Dark Age Greece: Odysseus and his hetairoi», en Gill, C., Postlethwaite, N. y Seaford, R. (eds.), pp. 51-73.

Evans, J. A. S. 1963: «Histiaeus and Aristagoras», AJPh 84, p. 113-128.

Finley, M. 1977: Uso y abuso de la historia, Barcelona.

Finley, M. 1978: The World of Odysseus, Harmondsworth.

Gauthier, P. 1973: «Notes sur l'étranger et l'hospitalité en Grèce et à Rome», Ancient Society 4, pp. 1-21.

Gill, C., Postlethwaite, R. y Seaford, R. (eds.) 1998: Reciprocity in Ancient Greece, Oxford.

Goldhill, S. D. 1986: Reading Greek Tragedy, Cambridge.

Gouldner, A. W. 1960: «The Norm of Reciprocity: A Preliminary Statement», American Sociological Review 25, pp. 161-178.

Greenwood, E. 2007: «Bridging the narrative (5. 23-7)», en Irwin, E. \& Greenwood, E. (eds.) Reading book V. A Study of the logoi in Book 5 of Herodotus' Histories, Cambridge, pp. 128-145.

Gregory, C. A. 1982: Gifts and Commodities, Londres.

Hammond, N. G. L. 1955: «Studies in Greek Chronology of the sixth and fifth centuries B. C.», Historia 4, pp. 371-411.

Hansen, M. H. 1991: The Athenian Democracy in the Age of Demosthenes. Structures, principles and ideology, Oxford.

Herman, G. 1987: Ritualised friendship and the Greek City, Cambridge.

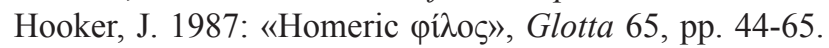

How, W. y Wells, J. 1936: A Commentary on Herodotus, Oxford.

Hude, C. 1927: Herodotus, Oxford.

Immerwahr, H. R. 1957: «The Samian Stories of Herodotus», CJ 52, pp. 312-22.

Immerwahr, H. R. 1966: Form and Thought in Herodotus, Cleveland.

Kakridis, H. J. 1963: La notion de l'amitié et de l'hospitalité chez Homère, Tesalónica. 
Karavites, P. 1992: Promise-giving and Treaty-making. Homer and the Near East, Leiden.

Keinast, D. 2002: «Bemerkungen zum Jonischen Aufstand und zur Rolle des Artaphernes», Hist 51, pp. 1-31.

Konstan, D. 1997: Friendship in the Classical World, Cambridge.

Lacey, W. K. 1968: The family in Classical Greece, Londres-Southampton.

Low, P. 2007: Interstate Relations in Classical Greece: Morality and Power, Cambridge.

Mac Cormack, G. 1976: «Reciprocity», Man 11, pp. 89-103.

Marek, Ch. 1984: Die Proxenie, Frankfurt.

Mauss, M. 1970: The gift: Form and Functions of Exchange in Archaic Society, Nueva York.

Millett, P. C. 1991: Lending and Borrowing in Ancient Athens, Cambridge.

Mitchell, B. M. 1975: «Herodotus and Samos», JHS 95, pp. 75-91.

Mitchell, L. 1997: Greeks Bearing Gifts: The Public Use of Private Relationships in the Greek World, 435-323 BC., Cambridge.

Monro, D. y Allen, T. 1920: Homeri Opera in five volumes, Oxford.

Morris, I. 1986: «The Use and Abuse of Homer», Classical Antiquity 5, pp. 81-138.

Mosley, D. 1973: Envoys and Diplomacy in Ancient Greece, Historia Einzelschriften 22, Wiesbaden.

Munson, R. V. 2007: «The trouble with the Ionians: Herodotus and the beginning of the Ionian Revolt (5.28-38.1)», en Irwin, E. y Greenwood, E. (eds.) Reading book $V$. A Study of the logoi in Book 5 of Herodotus' Histories, Cambridge - Nueva York, pp. 146-167.

Murray, O. 1988: «The Ionian Revolt», en Boardman, J. et al., (eds.) The Cambridge Ancient History. IV, Cambridge, pp. 461-490.

Murray, O. 1990: «The Affair of the Mysteries: Democracy and the Drinking Cup», en Murray, O. (ed.), Sympotica: A Symposium on the Symposion, Oxford, pp. 149-161.

Nenci, G. 1994: Erodoto. La rivolta della Ionia. V Libro delle Storie, Milán.

Neville, J. 1979: «Was there an Ionian Revolt?», CQ 29, pp. 268-275.

Osborne, C. 1994: Eros Unveiled: Plato and the God of Love, Oxford.

Panessa, G. (ed.) 1999: Philiai I, Pisa.

Pitt-Rivers, J. 1973: «The kith and the kin», en Goody, J. (ed.), The Character of Kingship, Cambridge, pp. 89-105.

Reece, S. 1993: The Stranger's Welcome: Oral Theory and the Aesthetics of the Homer Hospitality Scene, Ann Arbor.

Robinson, D. 1990: «Homeric pínos: love of life and limbs, and friendship with one's $\theta 0 \mu o ́ s »$, en Craik, E. M. (ed.), "Owls to Athens»: Essays on Classical Subjects presented to Sir Kenneth Dover, Oxford, pp. 97-108. 
Rösler, W. 1980: Dichter und Gruppe: Eine Untersuchung zu den Bedingungen und zur historischen Funktion früher griechischer Lyrik am Beispiel Alkaios, Múnich.

Santiago Álvarez, R. 2004: «La familia léxica de xénos en Homero: usos y significados, II (Odisea)», Faventia 26, pp. 25-42.

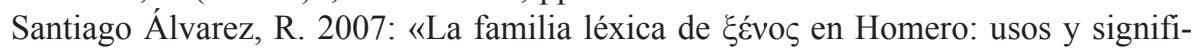
cados, I (Ilíada)», en Alonso Aldama, J., García Román, C. y Mamolar Sánchez,

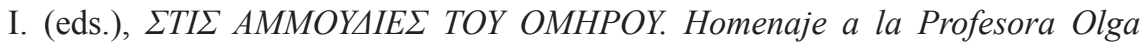
Omatos, Vitoria-Gasteiz, pp. 733-742.

Santiago Álvarez, R. 2013: «La polaridad huésped/extranjero en los poemas homéricos» en Santiago Álvarez, R. y Oller Guzmán, M. (eds.), Contacto de poblaciones y extranjería en el mundo griego antiguo. Estudio de fuentes, pp. 29-45.

Schmitt-Pantel, P. 1990 : «Sacrificial meal and Symposion: two models of civic institutions in the archaic city?», en Murray, O. (ed.), Sympotica: A Symposium on the Symposion, Oxford, pp. 14-33.

Schmitt-Pantel, P. 1997: La cite au banquet: Histoire des repas publics dans les cités grecques, Roma.

Schwartz, M. 1985: «Scatology and eschatology in Zoroaster», en Papers in Honor of Professor Mary Boyce. II, Acta Iranica 25, Berkeley, pp. 188-191.

Scott, L. 2005: A Historical Commentary on Herodotus 6, Leiden.

Seaford, R. 1994: Reciprocity and Ritual. Homer and Tragedy in the Developing City-State, Oxford.

Stadter, P. A. 2002: «Historical thought in ancient Greece», en Kramer, L. y Maza, S. (eds.), A Companion to Western Historical Thought, Oxford, pp. 35-59.

Stehle, E. M. 1994: «Cold meat: Timokreon on Themistocles», AJPh 115, pp. 507-524.

Tausend, K. 1992: Amphyktionie und Symmachie. Formen zwischenstaatlicher Beziehungen im archaischen Griechenland, Stuttgart.

Tozzi, P. 1978: La rivolta ionica, Pisa.

van Wees, H. 1992: Status Warriors: War, Violence and Society in Homer and History, Amsterdam.

Vernant, J. P. 1965: Los orígenes del pensamiento griego, Buenos Aires.

von Reden, S. 1995: Exchange in Ancient Greece, Londres.

Walbank, M (1978): Athenian Proxenies of the Fifth Century, Toronto - Sarasota.

Wallace, M. B. 1970: «Early Greek proxenoi», Phoenix 24, pp. 189-208.

Will, E. 1997: El mundo griego y el Oriente, T. I. El Siglo V (510-403), Madrid.

Fecha de recepción de la primera versión del artículo: 10/04/2015

Fecha de aceptación: 30/09/2015

Fecha de recepción de la versión definitiva: 19/10/2015 